\title{
Relation between IgG and IgA antibody titres against Helicobacter pylori in serum and severity of gastritis in asymptomatic subjects
}

\author{
J Kreuning, J Lindeman, I Biemond, C B H W Lamers
}

\begin{abstract}
Aims-To investigate whether the absorbance index of IgG and IgA antibodies against Helicobacter pylori is related to a semiquantitative assessment of the density of $\boldsymbol{H}$ pylori colonisation in gastric biopsy specimens and to the severity of gastritis.

Methods-The grade of gastritis was scored separately for antral and fundic mucosa using three different classifications. Serum IgA and IgG antibodies against $H$ pylori were measured by ELISA. The density of gastric $H$ pylori colonisation was graded semiquantitatively from 0 to 3.
\end{abstract}

Results-Among 48 healthy volunteers studied, 17 were found to have gastritis according to Whitehead's criteria. $H$ pylori was present in the biopsy specimens of 14 of 17 subjects with gastritis. The IgG $H$ pylori antibody absorbance index was significantly $(p<0.05)$ correlated not only with the density of antral $H$ pylori colonisation, but also with the degree of gastritis of the antrum, as assessed by the Whitehead score, activity, and the Sydney system $(p<0.05)$. The IgA $H$ pylori antibody absorbance index was significantly correlated with the Whitehead score and Sydney system, but not with the activity score of the antrum or with the density of antral gastric $H$ pylori infection. There were no significant correlations between the IgG $H$ pylori antibody absorbance index and the gastritis scores of the fundus mucosa and the density of $H$ pylori infection of the gastric body. The IgA $H$ pylori antibody absorbance index was only significantly $(p<0.05)$ correlated with the density of $H$ pylori colonisation and the Sydney system gastritis score of the corpus.

Conclusions-The serological absorbance index of IgG antibodies against $H$ pylori is related to the severity of antral gastritis and the density of antral $H$ pylori colonisation. Thus a high absorbance index of IgG antibodies against $H$ pylori points to severe antral gastritis and dense $H$ pylori colonisation of the antrum.

$(\mathfrak{F}$ Clin Pathol 1994;47:227-231)
Chronic gastritis is associated with gastric Helicobacter pylori infection and increased serum antibodies against the organism. ${ }^{12} \mathrm{~A}$ previous study found a higher mean antibody titre in active chronic gastritis than in chronic gastritis, ${ }^{3}$ and we were interested to study whether the absorbance index of IgG and IgA $H$ pylori antibodies was correlated with the severity of gastritis. If such a correlation existed, serology could be used to assess the severity of gastritis without endoscopy. To obviate possible confounding factors, such as gastric complaints, peptic ulcer, or use of drugs, we studied a group of healthy subjects without a history of gastrointestinal disorders or other chronic disease.

\section{Methods}

Forty eight asymptomatic volunteers, 29 of whom were members of the hospital staff, were examined. Their ages ranged from 19 to 58 years, with a mean age of 33 years. There were 22 women and 26 men. The mean age of the two groups was similar-33 for the women and 34 for the men. Volunteers with any clinical history of gastrointestinal disease or use of anti-ulcer drugs were excluded. The study protocol was approved by the ethics committee of the University Hospital Leiden. Informed consent was obtained from all volunteers before examination.

Endoscopy was performed after an overnight fast, with an Olympus GIF-K $30^{\circ}$ forward-oblique viewing fibreoptic endoscope. Biopsy specimens were obtained from seven standard sites in the stomach (three from the gastric antrum and four from the corpus). The specimens were fixed immediately in $10 \%$ neutral buffered formalin. Before endoscopy, venous blood was withdrawn and the serum was stored at $-70^{\circ} \mathrm{C}$ until assay.

\section{HISTOLOGICAL ANALYSIS}

The specimens were stained with haematoxylin and eosin, periodic acid Schiff, toluidine blue, and by James's reticulin method. All biopsy specimens were examined blind by an expert pathologist (JL). The specimens of antrum and corpus were classified as follows: (1) the criteria of Whitehead, ${ }^{4}(2)$ the Sydney system, ${ }^{5}$ and (3) an acute gastritis score. ${ }^{6}$ These classifications emphasise different 
features of gastritis: the Whitehead classification emphasises superficial and atrophic mucosal changes; the activity score the degree of polymorphonuclear and mononuclear leucocyte infiltration; and the Sydney system both infiltration and mucosal changes.

According to Whitehead et $a l^{7}$ the degree of gastritis is expressed in quantitative terms, so each degree of gastritis was scored from 0-4 according to the following scheme: normal $=0$, superficial gastritis $=1$, mild atrophic gastritis $=2$, moderate atrophic gastritis $=3$, severe atrophic gastritis $=4$. In this analysis activity and metaplasia were not taken into account. Because the highest possible mean score is 4 , multiplication of the mean scores by 25 yields a gastritis index ranging from 0 to 100 .

Each parameter in the Sydney systeminflammation, activity, atrophy and intestinal metaplasia-was scored from $0-3$ (0 is none, 1 is mild, 2 is moderate, 3 is severe). The total maximal score for these four parameters varied from $0-12$. In the activity score the following parameters were scored: density of the inflammatory infiltrate in the lamina propria (0-2); density of polymorphonuclear leucocytes in the lamina propria (0-3); presence of intraepithelial polymorphonuclear leucocytes (0-3); and superficial erosions (0-2). The total score varied from $0-10$. To compare the three different classifications the scores of the Sydney system and the activity score were multiplied by a factor of 8.3 and 10 , respectively, to obtain a gastritis index from $0-100$ for each score. Figures 1 and 2 show samples of the three different classifications.

All biopsy specimens were also examined for the presence of $H$ pylori. If present, the density of mucosal $H$ pylori colonisation was graded semiquantitatively from 0 to 3 .

Figure 1 Chronic active gastritis of antrum mucosa with severe atropy: total score according to the Whitehead classification 4, gastritis index 100; total score according to the activity score 3, gastritis index 30; total score according to the Sydney system 6 , gastritis index 50.

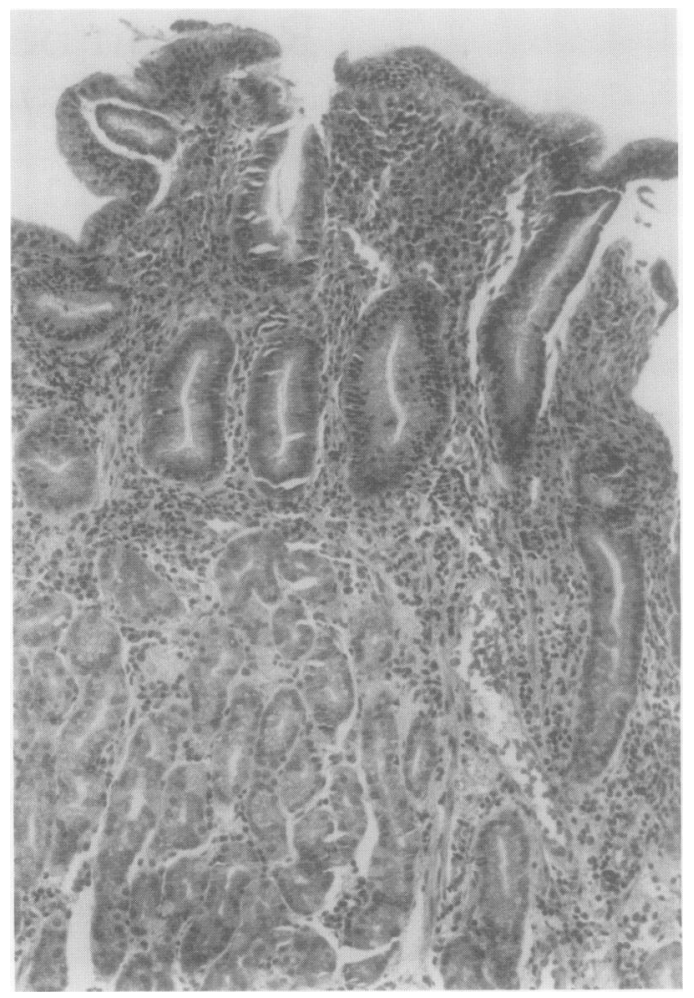

Figure 2 Chronic gastritis of fundic mucosa with moderate atropy: total score according the Whitehead classification 3, gastritis index 75; total score according to the activity score 2, gastritis index 20; total score according to the Sydney system 4, gastritis index 33.

\section{SEROLOGY}

Specific IgA and IgG antibodies against $H$ pylori were measured using a modified enzyme linked immunosorbent assay (ELISA). Microtitre plates were coated with a homogenate of six strains of $H$ pylori. Specific antibodies from diluted sera were detected by conjugates of horseradish peroxidase and goat antibodies specific for human IgA or IgG. The amount of bound peroxidase was measured through reaction of hydrogen peroxide and a chromogenic substrate, whose optical density (OD) was read by a photometer. Readings of unknown sera were compared with those of a high reference serum. The results were expressed as the absorbance index (AI):

$\mathrm{Al}=$

mean OD reading $(n=2)$ of patients' serum - mean OD of blank reading Mean OD reading $(n=2)$ of reference serum - mean OD of blank reading

The procedure of the assay and determination of intra- and interassay variability of the ELISA has been described in detail by Peña $e t$ $a l .{ }^{8}$ Serum with an $\mathrm{Al}$ of $>0.35$ for IgA antibodies to $H$ pylori and an $\mathrm{Al}$ of $>0.32$ for $\mathrm{IgG}$ antibodies to $H$ pylori were considered evidence of $H$ pylori infection.

Results were expressed as the mean (SE). The relations between the absorbance indices of IgG and IgA $H$ pylori antibodies, the degree of $H$ pylori colonisation of antrum and corpus, and the severity of gastritis according to the three different classifications were separately analysed by linear regression, and the correlation coefficient was inferred by two-tailed significance. 
For obvious reasons these analyses could be performed only in subjects with histological evidence of gastritis.

Results

Seventeen of the 48 asymptomatic subjects had gastritis of the antrum and 16 gastritis of the corpus according to the criteria of Whitehead and the Sydney system. Results in these 17 subjects were further analysed. These 17 subjects comprised six men and 11 women with a mean age of 39 years. According to the activity score, 15 of these 17 subjects had gastritis of the antrum and corpus.

There were significant correlations in the

Figure 3 Individual scores of gastritis of the gastric antrum as assessed by the Whitehead classification (lefi panel), activity score (middle panel), and the Sydney system (right panel). Cross symbols denote Helicobacter pylori colonisation.

Figure 4 Individual scores of gastritis of the gastric corpus as assessed by the Whitehead classification (left panel), activity score (middle panel), and the Sydney system (right panel). Cross symbols denote

Helicobacter pylori colonisation.
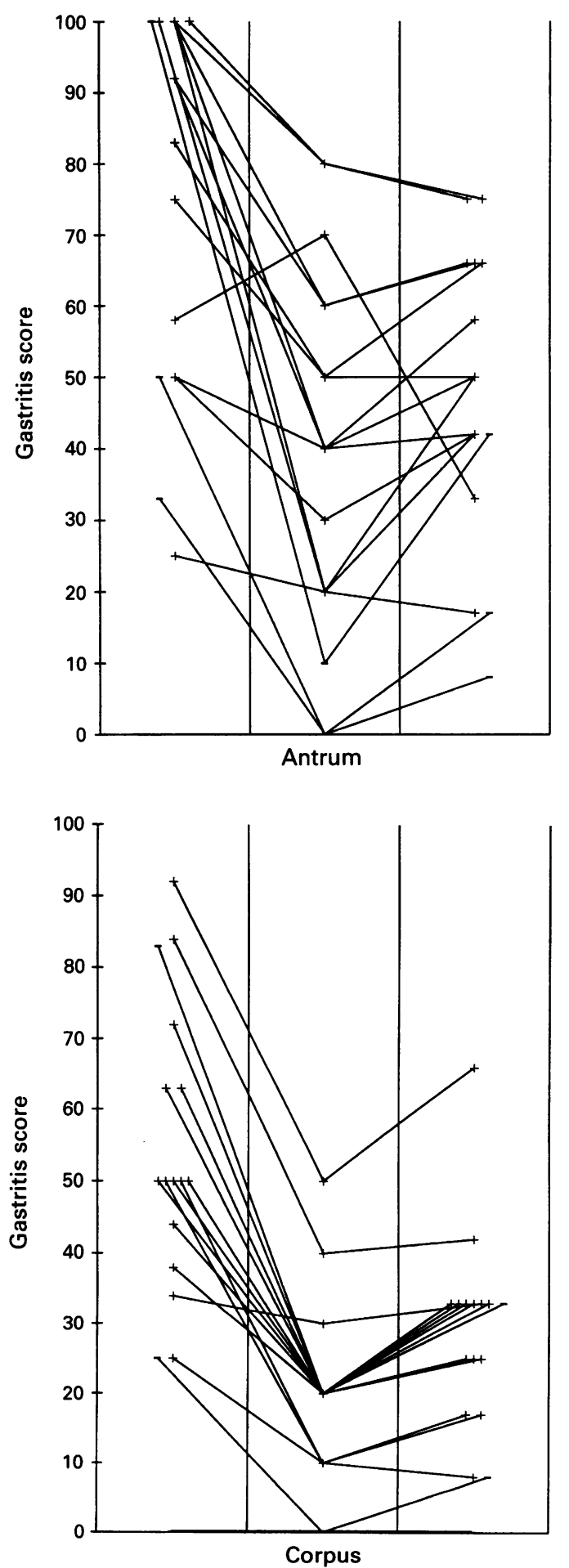

antral mucosa between the Whitehead classification and the Sydney system scores $(r=0.80$; $\mathrm{p}<0.001$ ), and between the Sydney system and the activity scores $(r=0.78 ; p<0.001)$. The individual histological scores of the antral mucosa are presented in fig 3 . There were also significant correlations in the gastric corpus between the Whitehead classification and the Sydney system scores $(r=0.85 ; \mathrm{p}<0.001)$ and the activity score $(r=0.75 ; p<0.002)$, and between the Sydney system and the activity scores $(r=0.94 ; p<0.001)$. The individual histological scores of the fundus mucosa are shown in fig 4.

$H$ pylori was observed in 10 subjects in the entire stomach and in four cases in the antrum alone. In 13 of these 14 subjects the absorbance index of IgG antibodies to $H$ pylori was higher than 0.32 , but only nine of these subjects had a raised absorbance index of IgA antibodies to $H$ pylori above 0.35 .

There was a significant correlation between the absorbance index of IgG antibodies to $H$ pylori and the degree of gastritis of the antrum as assessed by all three gastritis scores (table 1). Individual data on the absorbance index of IgG antibodies to $H$ pylori and the severity of gastritis according to the Whitehead score is shown in fig 5. The absorbance index of IgA antibodies was only significantly correlated with the Whitehead classification and Sydney system scores, but not the activity score (table 1).

There was no correlation between the absorbance index of IgG antibodies and the different gastritis scores of the corpus (table 2 ). For the corpus there was a significant correlation only between the absorbance index

Table 1 Correlations between serum absorbance indices of $\operatorname{Ig} A$ and $\operatorname{Ig} G$ antibodies against $H$ pylori and degree of $H$ pylori colonisation and severity of gastritis of the antrum

\begin{tabular}{llll}
\hline & $\begin{array}{l}\text { IgA } \\
\text { antibodies } \\
(A l)\end{array}$ & $\begin{array}{l}\text { IgG } \\
\text { antibodies } \\
(A l)\end{array}$ & Colonisation \\
\hline Colonisation & $\mathrm{p}>0.10$ & $\begin{array}{l}0.50 \\
\mathrm{p}=0.04\end{array}$ & \\
Gastritis & $\mathrm{p}$ & $\mathrm{r}=0.52$ & $\mathrm{r}=0.46$ \\
$\quad$ Whitehead score) & $\mathrm{r}=0.65$ & $\mathrm{r}=0.03$ & $\mathrm{p}=0.07$ \\
Gastritis & $\mathrm{p}=0.005$ & $\mathrm{p}=0.03$ & \\
$\quad$ (activity score) & $\mathrm{p}>0.10$ & $\mathrm{p}=0.52$ & $\mathrm{r}=0.69$ \\
Gastritis & $\mathrm{p}=0.03$ & $\mathrm{p}=0.002$ \\
$\quad$ (Sydney system) & $\mathrm{r}=0.62$ & $\mathrm{r}=0.61$ & $\mathrm{r}=0.63$ \\
& $\mathrm{p}=0.008$ & $\mathrm{p}=0.01$ & $\mathrm{p}=0.006$ \\
\hline
\end{tabular}

Table 2 Correlations between serum absorbance indices of $\operatorname{Ig} A$ and $\operatorname{Ig} G$ antibodies against $H$ pylori and degree of $H$ pylori colonisation and severity of gastritis of the gastric body

\begin{tabular}{|c|c|c|c|}
\hline & $\begin{array}{l}\text { IgA } \\
\text { antibodies } \\
\text { (Al) }\end{array}$ & $\begin{array}{l}\text { IgG } \\
\text { antibodies } \\
\text { (Al) }\end{array}$ & Colonisation \\
\hline Colonisation & $\begin{array}{l}r=0.51 \\
\mathrm{p}=0.04\end{array}$ & $\begin{array}{l}r=0.42 \\
p=0.10\end{array}$ & \\
\hline $\begin{array}{l}\text { Gastritis } \\
\text { (Whitehead score) }\end{array}$ & $\begin{array}{l}r=0.47 \\
p=0.06\end{array}$ & $p>0.10$ & $p>0.10$ \\
\hline $\begin{array}{l}\text { Gastritis } \\
\quad \text { (activity score) }\end{array}$ & $\begin{array}{l}r=0.45 \\
p=0.07\end{array}$ & $p>0.10$ & $p>0.10$ \\
\hline $\begin{array}{l}\text { Gastritis } \\
\text { (Sydney system) }\end{array}$ & $\begin{array}{l}r=0.55 \\
p=0.02\end{array}$ & $\begin{array}{l}r=0.42 \\
p=0.09\end{array}$ & $\begin{array}{l}\mathrm{r}=0.46 \\
\mathrm{p}=0.06\end{array}$ \\
\hline
\end{tabular}




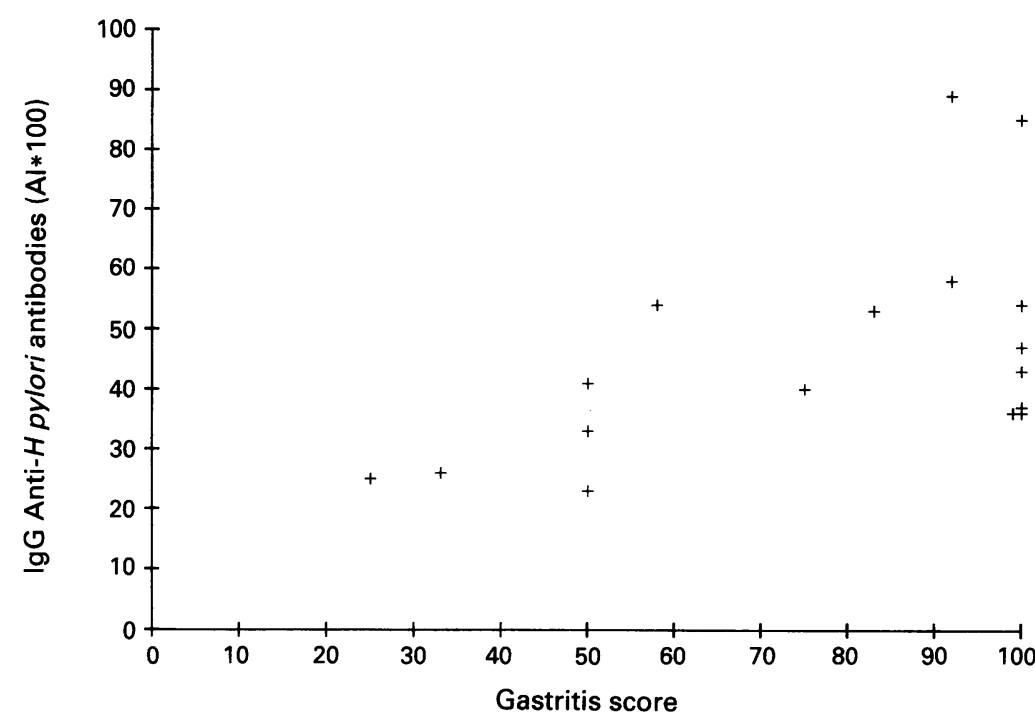

Figure 5 Correlation between the serum absorbance index of IgG antibodies to Helicobacter pylori and the gastritis score of the antrum according to the Whitehead classification $(r=0.52 ; p=0.03)$. to the severity of gastritis. We were also interested to see if there was any association between the number of bacteria semiquantitatively assessed in the biopsy specimens, and the titres of the antibodies and the severity of gastritis. Endoscopic biopsy specimens of antrum and corpus were scored and analysed separately.

To obviate possible confounding factors, such as gastric complaints, peptic ulcer, or use of drugs, we studied a group of healthy subjects without a history of gastrointestinal disorders or other chronic disease. Seventeen of them had gastritis and they formed the study population for this investigation. Fourteen of them had histological and serological evidence of $H$ pylori infection. Thus the incidence of $H$ pylori infection in Dutch asymptomatic subjects is about $30 \%$. Although the inclusion of a number of endoscopists as volunteers in this study may have affected this result, the percentage is in line with the results of Dutch blood donors of similar age. ${ }^{11}$

Several interesting results were obtained. of IgA antibodies and the Sydney system gastritis score of the corpus (table 2).

The absorbance index of IgG antibodies to $H$ pylori was significantly correlated with the degree of $H$ pylori colonisation of the antrum $(r=0.50 ; p=0.04)$, but not of the corpus $(r=0.42 ; p=0 \cdot 10)$. In contrast, the absorbance index of $\operatorname{IgA}$ antibodies was significantly correlated with the degree of $H$ pylori colonisation of the corpus ( $\mathrm{r}=0.51$; $\mathrm{p}=0.04)$, but not of the antrum $(\mathrm{p}>0 \cdot 10)$.

The degree of $H$ pylori colonisation of the antrum was correlated to the severity of gastritis in the antrum (table 1), but not to the severity of body gastritis. Furthermore, the density of $H$ pylori colonisation of the gastric body was not significantly correlated with the severity of body gastritis, but there was a significant correlation between the degree of $H$ pylori colonisation of the corpus and the severity of gastritis in the antrum according to the Whitehead classification $(r=0.49 ; p=0.045)$ and the Sydney system scores $(r=0.55$; $\mathrm{p}=0.02$ ).

\section{Discussion}

It has repeatedly been shown that the titres of IgA and IgG antibodies to $H$ pylori in serum can be used as non-invasive tests for the presence of gastric $H$ pylori infection and gastritis. ${ }^{12}$ It is, however, not known whether the titres of $H$ pylori antibodies in serum are indicative of the severity of gastritis. If so, the severity of gastritis could be assessed and followed without endoscopy. Goodwin et $\mathrm{al}^{3}$ reported a higher mean antibody titre in active chronic than in inactive chronic gastritis. In contrast, Booth et $a l^{9}$ and Newell et al ${ }^{10}$ did not find higher titres of $\mathrm{H}$ pylori antibodies in severe gastritis, although in the last study a tendency to a higher concentration in more severe gastritis was observed.

In this study we therefore attempted to answer the question as to whether the titres of IgG or IgA antibodies to $H$ pylori are related
Clinically, the most important finding is that the concentration of IgG antibodies to $H$ pylori in serum correlates with the severity of gastritis of the antrum according to all three classification systems. The absorbance index of IgG antibodies in serum was correlated with the degree of colonisation of the antrum by $H$ pylori. Thus a high IgG antibody titre to $H$ pylori points to severe antrum gastritis with intense colonisation of the antrum. This finding may facilitate studies of the severity of gastritis without the need for endoscopic biopsies.

Little is known about the relation between serum $H$ pylori antibodies and the severity of gastritis in Western people. In Chinese subjects the serum antibody titres to urease were related to the bacterial numbers of $H$ pylori in gastric mucosa, but no relation with the severity of gastritis was found. ${ }^{12}$ In Malawians with epigastric pain of more than two weeks, there was an association between the density of colonisation with $H$ pylori and the degree of polymorphonuclear and mononuclear cell infiltration, as found in our study, but the relation between the concentration of IgG antibodies to $H$ pylori in serum and the severity of gastritis was not assessed. ${ }^{13}$

In conclusion, this study shows that determining the absorbance index of IgG antibodies to $H$ pylori in serum could be used to assess the severity of gastritis of the antrum.

We are indebted to Mrs Ineke Kuiper for technical, and Mrs Louise Niepoth for secretarial, assistance.

1 Perez-Perez GI, Dworkin BM, Chodos JE, Blaser MJ Campylobacter pylori antibodies in humans. Ann Intern Med 1988;109:11-7.

2 Jones DM, Eldridge J, Fox AJ, Sethi P, Whorwell PJ Antibody to the gastric campylobacter-like organism "Antibody to the gastric campylobacter-like organism ("Campylobacter pyloridis")-clinical correlations and distribution in the

3 Goodwin CS, Blincow E, Peterson G, Sanderson C, Cheng W, Marshall B, et al. Enzyme-linked immunosorbent assay for Campylobacter pyloridis: correlation with presence of $\mathrm{C}$ pyloridis in the gastric mucosa. f Infect Dis 1987;155:488-94. London: WB Saunders, 1990.
4 Whitehead R. Mucosal biopsy of the gastrointestinal tract. 
5 Price AB. The Sydney system: histological division. f Gastroenterol Hepatol 1991;6:209-22.

6 Rauws EAJ, Langenberg W, Houthoff J, Zanen HC Tytgat GNJ. Campylobacter pyloridis-associated chronic active antral gastritis. Gastroenterology 1988;94 33-40.

7 Whitehead R, Roca M, Truelove SC. Antro-duodenitis in duodenal ulcer and in non-ulcer dyspepsia. In: Wastell $\mathrm{C}$, ed. Chronic duodenal ulcer. London: Butterworth, 1974:17-23.

8 Peña AS, Endtz HPh, Offerhaus GJA, HoogenboomVerdegaal A, van Duijn W, de Vargas N, et al. Value of serology (ELISA and immunoblotting) for the diagnosi of Campylobacter pylori infection. Digestion 1989;44: $131-41$

9 Booth L, Holdstock G, MacBride H, Hawtin P, Gibson JR, Ireland A, et al. Clinical importance of Campylo- bacter pyloridis and associated serum IgG and IgA antibody responses in patients undergoing upper gastrointestinal endoscopy. $₹$ Clin Pathol 1986;39:215-19.

10 Newell DG, Johnston BJ, Ali MH, Reed PI. An enzymelinked immunosorbent assay for the serodiagnosis of Campylobacter pylori-associated gastritis. Scand $f$ Gastroenterol 1988;23(suppl 142):53-7.

11 Veenendaal RA, Biemond I, Peña AS, van Duijn W, Kreuning J, Lamers CBHW. Influence of age and Helicobacter pylori infection on serum pepsinogens in healthy blood transfusion donors. Gut 1992;33:452-5.

12 Chen Z. ELISA for detection of anti-urease antibodies of Campylobacter pylori and its application. Chinese Med $\mathcal{F}$ 1991;71:434-7.

13 Harries AD, Stewart M, Deegan KM, Mughogho GK, Wirima J, Hommel $M$, et al. Helicobacter pylori in Malawi, central Africa. F Infection 1992;24:269-76. 